This document is the Accepted Manuscript version of a Published Work that appeared in final form in Macromolecules, copyright (C) American Chemical Society after peer review and technical editing by publisher. To access the final edited and published work see

https://dx.doi.org/10.1021/acs.macromol.6b02726

\title{
Using Pyrene Excimer Fluorescence to Probe Polymer Diffusion in
}

\section{Latex Films}

\author{
Remi Casier, Mario Gauthier*, Jean Duhamel*
}

Institute for Polymer Research, Waterloo Institute for Nanotechnology, Department of

Chemistry, University of Waterloo, 200 University Avenue West, Waterloo, Ontario, N2L 3G1, Canada

* To whom correspondence should be addressed. 


\section{Abstract}

This study introduces a simple technique that can be used to quantitatively probe interparticle polymer diffusion (IPD) between adjacent particles in a latex film using pyrene excimer fluorescence (PEF). To demonstrate the validity of the technique, four latexes were prepared; two pyrene-labeled poly(n-butyl methacrylate) (Py-PBMA) latexes and two non-fluorescent PBMA latexes. The two pairs of Py-PBMA and PBMA latexes had similar distributions of polymer molecular weight and particle diameters. Mixtures of latex dispersions having a composition of $5 \mathrm{wt} \%$ Py-PBMA latex and $95 \mathrm{wt} \%$ non-fluorescent PBMA latex were cast into films. Fluorescence spectra of the films were acquired and the ratio of the fluorescence intensities for the pyrene monomer $\left(I_{\mathrm{M}}\right)$ and excimer $\left(I_{\mathrm{E}}\right)$ was calculated to determine the $I_{\mathrm{E}} / I_{\mathrm{M}}$ ratio. The latex films were then annealed at a constant temperature set between 75 and $119{ }^{\circ} \mathrm{C}$. The fraction of mixing $\left(f_{\mathrm{m}}\right)$, representing the amount of polymer having diffused out of a particle, was determined by monitoring the change in the $I_{\mathrm{E}} / I_{\mathrm{M}}$ ratio as a function of annealing time. The $f_{\mathrm{m}}$ profiles were then analysed to yield the polymer diffusion coefficients, and the apparent activation energy $\left(E_{a}\right)$ for diffusion was found to equal $179 \pm 7$ and $170 \pm 12 \mathrm{~kJ} \cdot \mathrm{mol}^{-1}$ for the high and low molecular weight chains, respectively. The $c_{1}$ and $c_{2}$ parameters in the WLF equation were calculated to be $11 \pm 2$ and $170 \pm 30 \mathrm{~K}$, respectively. The $E_{\mathrm{a}}$ values and $c_{1}$ and $c_{2}$ parameters were in close agreement with values previously found for PBMA by other techniques, suggesting that the PEF experiments provide a valid experimental means to probe IPD in latex films. The superiority of PEF over earlier procedures includes the extreme simplicity of the experimental method that involves the labeling of a single latex particle, and the use of ratios of fluorescence intensity. It opens new research venues in the study of IPD during latex film formation. 


\section{INTRODUCTION}

Over the years, latex dispersions have been widely used in many industrial applications. One main usage of latex dispersions is for decorative and protective purposes, where a latex dispersion is applied onto a surface to form a film. Film formation is typically divided into three stages: water evaporation, particle deformation, and particle coalescence. ${ }^{1-3}$ In the first stage, a latex dispersion is deposited on a substrate and the water is allowed to evaporate, leaving a layer of packed particles. In order for the subsequent stages of film formation to occur, the film must be heated above a minimum temperature, namely the minimum film formation temperature (MFT). As the layer of packed particles is heated above the MFT the particles begin to deform, filling in the voids left behind from the first stage. With continued annealing of the film, the polymer chains constituting the latex particles begin to diffuse across the particle boundaries in a process that ultimately leads to coalescence of the particles into a continuous film. It is during this final stage of film formation that a film develops both its mechanical integrity and the ability to protect a surface. ${ }^{1,3,4}$ As such, the quantitative determination of the extent of coalescence between particles is of high interest.

Over the past 30 years, several techniques have been developed to quantitatively probe polymer diffusion in latex films, but the two better known methods use small angle neutron scattering (SANS) $)^{4-6}$ and fluorescence resonance energy transfer (FRET). ${ }^{3,7-11}$ In SANS measurements, a deuterated latex is mixed in a matrix of non-deuterated latex. Using SANS, the radius of gyration of the deuterated latex particles could be monitored as a function of annealing time. Changes in the radius of gyration over time were described by a Fickian diffusion model, which was employed to determine the apparent diffusion coefficient of the deuterated polymer 
chains. Later on, Winnik et al. demonstrated that FRET could yield a diffusion coefficient for the chains in a latex film, but without using a neutron source as required for SANS. In these experiments, a film was prepared with equal amounts of a latex particle labeled with an energy donor, typically phenanthrene, and another one labeled with an energy acceptor, typically anthracene. Time-resolved fluorescence was then applied to acquire the fluorescence decay for the energy donor. Before the particles coalesced, the donors emitted primarily with their natural lifetime. As interparticle polymer diffusion (IPD) occurred, the donors and acceptors began to mix, resulting in an increase in the amount of FRET taking place between the donor and acceptor labels. The extent of FRET was monitored over annealing time to give the fraction of mixing, or extent of coalescence, between the latex particles, as a function of annealing time. Similarly to the SANS experiments, a Fickian diffusion model was applied to yield the apparent diffusion coefficient of the labeled chains over the course of film formation. More recent applications of the FRET procedure have investigated how the presence of crosslinked gel in the latex, ${ }^{12}$ the glass transition temperature of the polymer used to prepare the latex, ${ }^{13}$ polymer branching, ${ }^{14}$ the relative humidity of the environment, ${ }^{15-17}$ the presence of oligomers in the film, ${ }^{18}$ the nature of the plasticizer, ${ }^{19,20}$ and the particle size ${ }^{21}$ affect the diffusion of linear chain in a latex film.

Although FRET is a powerful tool to probe polymer diffusion during latex film formation, the present study demonstrates that the same information can be found in a much simpler manner using pyrene excimer fluorescence (PEF). The preparation of pyrene-labeled latex has already been described in the scientific literature and such fluorescent particles have been employed to probe the diffusion of oxygen in latex films containing clay, ${ }^{22}$ carbon nanotubes, ${ }^{23,24}$ or prepared with latex particles of different diameters. ${ }^{25}$ But to the best of our knowledge, PEF generated by pyrene-labeled latex has never been applied to probe IPD in latex 
films. When a pyrene fluorophore is excited by light, it can emit as a monomer. However, if this excited pyrene happens to come in contact with another ground-state pyrene, an excimer is formed. A steady-state spectrofluorometer can be employed to measure the fluorescence intensity for the monomer $\left(I_{\mathrm{M}}\right)$ and excimer $\left(I_{\mathrm{E}}\right)$, and the ratio $I_{\mathrm{E}} / I_{\mathrm{M}}$, is then calculated. As it turns out, the $I_{\mathrm{E}} / I_{\mathrm{M}}$ ratio is directly proportional to the local concentration of pyrene sensed by an excited pyrene, so that $I_{\mathrm{E}} / I_{\mathrm{M}}$ can be used to probe changes in local pyrene concentration during the annealing process. Using this principle, a latex consisting of polymer chains randomly labeled with pyrene will have a high local pyrene concentration, resulting in a high $I_{\mathrm{E}} / I_{\mathrm{M}}$ ratio. A film prepared from a mixture of a small amount of this fluorescent latex with a large excess of non-fluorescently labeled latex will initially exhibit the high $I_{\mathrm{E}} / I_{\mathrm{M}}$ ratio of the pyrene-labeled latex. As film formation occurs, and the polymer chains containing pyrene diffuse into the surrounding non-fluorescent particles, the local pyrene concentration decreases, resulting in a lower $I_{\mathrm{E}} / I_{\mathrm{M}}$ ratio. By monitoring the $I_{\mathrm{E}} / I_{\mathrm{M}}$ ratio over annealing time, the fraction of mixing $\left(f_{\mathrm{m}}\right)$ between latex particles can be determined.

To demonstrate the validity of this proposal, a latex made of poly(n-butyl methacrylate) randomly labeled with pyrene (Py-PBMA latex) was prepared via emulsion polymerization. A small amount of the Py-PBMA latex was then mixed with a large excess of a non-labeled PBMA latex having a similar polymer molecular weight distribution and particle diameter. The dispersion mixture was then deposited on a small quartz plate and left to dry. The resulting latex film contained a small amount of Py-PBMA particles where the local pyrene concentration was high. Upon heating the film above the MFT, the polymer chains began to diffuse between adjacent latex particles. The fraction $f_{\mathrm{m}}$ was determined as a function of time during the course of annealing. The profile of $f_{\mathrm{m}}$ as a function of time and temperature was then analysed to retrieve 
the polymer diffusion coefficient and the activation energy $\left(E_{\mathrm{a}}\right)$ for polymer diffusion. The $E_{\mathrm{a}}$ values were compared to those obtained by other techniques for the diffusion of similar polymers during latex film formation. The good agreement obtained between the parameters that describe the diffusion of PBMA during film formation determined by this study and by other techniques demonstrates the validity of the procedure based on PEF. Considering its simplicity originating from the use of a single fluorescently-labeled latex, and the analysis being based on the straightforward measure of a ratio of fluorescence intensities, this study opens new research venues to characterize latex film formation.

\section{EXPERIMENTAL}

Materials: Ammonium persulfate (APS, Sigma-Aldrich, 98\%), n-butyl methacrylate (BMA, Sigma-Aldrich, 99\%), dioctyl sodium sulfosuccinate (AOT, Sigma-Aldrich, 98\%), ethanol (Fisher Scientific, HPLC), methacrylic anhydride (MAAn, Sigma-Aldrich, 94\%), methanol (Sigma-Aldrich, 99.9\%), and tetrahydrofuran (distilled in glass, inhibitor-free, Caledon), were used as received. Deionized water (DIW) obtained from a Biopure Series 4400 Single Pass Reverse Osmosis system was used for the preparation of all the latex samples.

Pyrene-labeled Monomer Synthesis: The synthesis of 1-pyrenemethoxydiethoxyethyl methacrylate $\left(\mathrm{PyEG}_{3} \mathrm{MA}\right)$ has been described elsewhere. ${ }^{26}$ Its ${ }^{1} \mathrm{H}$ NMR spectrum is given as Figure S1.

Emulsion Polymerization: A semi-continuous emulsion polymerization technique was employed to produce a pyrene-labeled latex. A $125 \mathrm{~mL}$ straight-wall, three-neck reactor was equipped with a reflux condenser, a mechanical stirrer, and a thermocouple probe. The reactor was charged with DIW $(66 \mathrm{~mL})$ and the AOT surfactant $(58 \mathrm{mg}, 0.13 \mathrm{mmol})$ before purging with nitrogen while stirring at $500 \mathrm{rpm}$ and heating to $80{ }^{\circ} \mathrm{C}$. A pre-emulsified monomer feed was 
prepared containing BMA (2.1 g, 15 mmol), PyEG 3 MA (0.31 g, $0.72 \mathrm{mmol})$, AOT (20 mg, 45 $\mu \mathrm{mol})$, and DIW ( $1 \mathrm{~mL})$. After the reactor reached the desired temperature, APS ( $5 \mathrm{mg}, 22 \mu \mathrm{mol})$ dissolved in DIW (1 mL) was added with a syringe through a needle into the reactor. DIW (1 $\mathrm{mL}$ ) was used to rinse the syringe and was also added to the reactor. After 5 minutes, monomer feeding into the reactor over a three hour period was started using a syringe pump. The latex was then filtered to remove any coagulum formed, resulting in a pyrene-labeled poly $(n$-butyl methacrylate) latex (Py-PBMA latex). Unlabeled PBMA latex was prepared by the same procedure, but using a monomer feed that contained only BMA (2.0 g, $14 \mathrm{mmol})$, AOT (19 mg, $43 \mu \mathrm{mol})$, and DIW (1 mL).

Latex Characterization: The particles were first analyzed using dynamic light scattering (DLS) measurements to determine the particle size and the particle size dispersity (PSD). A Malvern Zetasizer Nano Seriese instrument was used for the DLS measurements. The scattered light intensity was measured at $173^{\circ}$ from the incident beam at a temperature of $25^{\circ} \mathrm{C}$. The cumulant method was used to find the Z-average particle size, and the PSD was calculated as the square of the standard deviation over the mean of the particle size.

Gel permeation chromatography (GPC) was used to characterize the polymer molecular weight and dispersity $(\bigoplus)$. Samples dissolved in THF (ca. $2 \mathrm{mg} \cdot \mathrm{mL}^{-1}$ ) were injected into a series of three PolyAnalytik SupeRes mixed bed columns on a Viscotek VE 2001 GPC sample module equipped with a TDA 305 triple detector array and a $2600 \mathrm{UV}$ detector, using THF as the mobile phase. The columns were maintained at a temperature of $35{ }^{\circ} \mathrm{C}$ and the flow rate was 1 $\mathrm{mL} \cdot \mathrm{min}^{-1}$. The differential refractive index (DRI) and light scattering detectors were used to determine the absolute molecular weight and $\oslash$ of the polymer chains. The UV absorbance at a 
wavelength of $344 \mathrm{~nm}$ was also collected to confirm the incorporation of the pyrene label in the polymer.

The pyrene content of the polymers was determined using a Cary 100 Bio UV-visible spectrophotometer. Samples were prepared using distilled in glass THF and placed in a $1 \mathrm{~cm}$ path length cell. The polymers were recovered from the emulsion by four cycles of precipitation from THF into methanol. After measuring the absorbance for a solution with a known mass concentration of polymer, the molar fraction of pyrene-labeled monomer incorporated into the polymer backbone $\left(f_{\mathrm{Py}}\right)$ was found using Equation 1.

$$
f_{P y}=\frac{M_{B M A}}{\lambda_{P y}{ }^{-1}+M_{B M A}-M_{P y L M}}
$$

In Equation 1, $M_{\mathrm{BMA}}$ and $M_{\mathrm{PyLM}}$ are the molecular weight of butyl methacrylate and the pyrenelabeled monomer, equal to 142 and $433 \mathrm{~g} \cdot \mathrm{mol}^{-1}$, respectively. The number of moles of pyrene per gram of polymer $\left(\lambda_{\mathrm{Py}}\right)$ was obtained by taking the ratio of the molar concentration of pyrene over the massic concentration of polymer for a Py-PBMA solution in THF. The concentration of pyrene was found using the measured absorbance at $344 \mathrm{~nm}$ and the molar absorption coefficient of $\mathrm{PyEG}_{3} \mathrm{OH}$ in THF $\left(\varepsilon_{\mathrm{Py}}=42,700 \mathrm{M}^{-1} \cdot \mathrm{cm}^{-1}\right)$.

Film Preparation: Films were prepared from a $20 \mathrm{~g} \cdot \mathrm{L}^{-1}$ latex dispersion, where the solid was composed of $5 \mathrm{wt} \%$ of Py-PBMA latex and $95 \mathrm{wt} \%$ of non-fluorescent PBMA latex. The solution (ca. $0.5 \mathrm{~mL}$ ) was then cast onto a $1 \mathrm{~cm} \times 3 \mathrm{~cm}$ quartz plate, which was left to dry under nitrogen overnight. Once dried, the film was annealed by placing it in a glass tube submerged in a constant temperature oil bath. The tube was equipped with a thermocouple and sealed with a rubber septum. A nitrogen atmosphere was maintained using a check-valve bubbler connected to a needle inserted into the septum. To measure the fluorescence spectrum for the film as a 
function of annealing time, the film was removed from the glass tube and quickly cooled to room temperature on an aluminum block. The steady-state fluorescence spectrum of the film was acquired, and the sample was placed back into the glass tube for further annealing. A homogeneous film was also prepared by dissolving the annealed film in THF, and redepositing the polymer solution in THF on the quartz plate. The THF was evaporated under nitrogen for one hour. The film on the quartz plate was then placed in a glass tube under nitrogen and annealed for another hour in the oil bath to ensure the complete removal of THF. The homogeneous film was used as a reference for a fully annealed film $\left(t_{\mathrm{an}}=\infty\right)$.

Steady-State Fluorescence Measurements: The fluorescence spectrum was acquired using a Photon Technology International steady-state fluorometer equipped with a xenon arc lamp. The samples were excited at a wavelength of $344 \mathrm{~nm}$ and the emission was scanned from 350 to 600 $\mathrm{nm}$ in $1 \mathrm{~nm}$ increments, at a scan rate of $10 \mathrm{~nm} \cdot \mathrm{s}^{-1}$, using a front-face geometry setup. The sample holder was set to an angle of $160^{\circ}$ relatively to the excitation beam, to minimize light scattering. The slit widths were set to $1 \mathrm{~nm}$ for excitation and $1 \mathrm{~nm}$ for emission. The $I_{\mathrm{E}} / I_{\mathrm{M}}$ ratio was calculated by taking the ratio of the fluorescence intensity for the excimer $\left(I_{\mathrm{E}}\right)$, integrated from 500 to $530 \mathrm{~nm}$, over that for the monomer $\left(I_{\mathrm{M}}\right)$, integrated from 392 to $398 \mathrm{~nm}$. The spectrum was acquired at three different positions on the film at each annealing time. Although the $I_{\mathrm{E}} / I_{\mathrm{M}}$ ratios at the three positions were similar, the changes in $I_{\mathrm{E}} / I_{\mathrm{M}}$ over increasing annealing times were always measured at the same positions on the film. All experiments were conducted with the films exposed to air as no difference was observed within experimental error in the measured $I_{\mathrm{E}} / I_{\mathrm{M}}$ ratios whether the fluorescence measurements were conducted with the films exposed to air or kept under a nitrogen atmosphere. More details on the comparison of the annealing experiments conducted under air or nitrogen are provided as SI. 


\section{RESULTS AND DISCUSSION}

Latex Preparation: Two pyrene-labeled poly( $n$-butyl methacrylate) (Py-PBMA) latexes were prepared according to the procedure outlined in the Experimental section. The full details on the synthesis can be found under Latex Preparation in the SI. The first Py-PBMA latex that was prepared (Py-PBMA-L1) had a particle diameter of $119 \mathrm{~nm}$ and a PSD of 0.02. Py-PBMA-L1 consisted in a copolymer with $M_{w}=820 \mathrm{~kg} \cdot \mathrm{mol}^{-1}$ and $D=1.9$ as determined by GPC analysis. The second Py-PBMA latex (Py-PBMA-L2) prepared for this study had a significantly lower $M_{w}$ $=360 \mathrm{~kg} \cdot \mathrm{mol}^{-1}$ and $\oslash=1.8$. DLS analysis yielded a particle diameter of $123 \mathrm{~nm}$ and a PSD of 0.01 for Py-PBMA-L2. The pyrene content of the copolymers was found to equal 1.9 and 1.8 mol\% for Py-PBMA-L1 and Py-PBMA-L2, respectively.

Two non-fluorescent PBMA latex samples were prepared with a particle size, PSD, $M_{w}$, and $\oslash$ values matching as closely as possible those of the two Py-PBMA latexes. Using these latexes, two films were studied. Film 1 and Film 2 were prepared with the high and low molecular weight polymers, respectively. Table 1 summarizes the properties of the latexes used to prepare each film, so that they would contain $5 \mathrm{wt} \%$ Py-PBMA-Latex in a $95 \mathrm{wt} \%$ PBMA latex matrix.

Table 1: Compositional overview for Films 1 and 2.

\begin{tabular}{|c|c|c|c|c|c|c|c|}
\hline \multirow{2}{*}{ Film } & Latex & $\begin{array}{c}\text { Latex Pyrene } \\
\text { Content } \\
(\mathrm{mol} \%)\end{array}$ & $\begin{array}{c}\text { Particle } \\
\text { Size } \\
(\mathrm{nm})\end{array}$ & PSD & $\begin{array}{c}M_{w} \\
\left(\mathrm{~kg} \cdot \mathrm{mol}^{-1}\right)\end{array}$ & $\nexists$ & $\begin{array}{c}\text { Weight } \\
\text { Fraction }\end{array}$ \\
\hline \multirow{2}{*}{1} & Py-PBMA-L1 & 1.9 & 119 & 0.02 & 820 & 1.9 & 0.05 \\
\cline { 2 - 9 } & PBMA-L1 & 0 & 96 & 0.01 & 1,000 & 2.0 & 0.95 \\
\hline \multirow{2}{*}{2} & Py-PBMA-L2 & 1.8 & 123 & 0.01 & 360 & 1.8 & 0.05 \\
\cline { 2 - 9 } & PBMA-L2 & 0 & 122 & 0.02 & 320 & 1.7 & 0.95 \\
\hline
\end{tabular}


Film Formation: Before a dry film was annealed it was stored at a temperature below the MFT, so that all the pyrene-labeled copolymer chains were confined within the individual particles. As annealing occurred at a temperature above the MFT, the copolymer chains began to diffuse out into the bulk as illustrated in Figure 1. As this happened, the equilibrium between isolated pyrene species and pyrene dimers described in Scheme 1 shifted to the left.

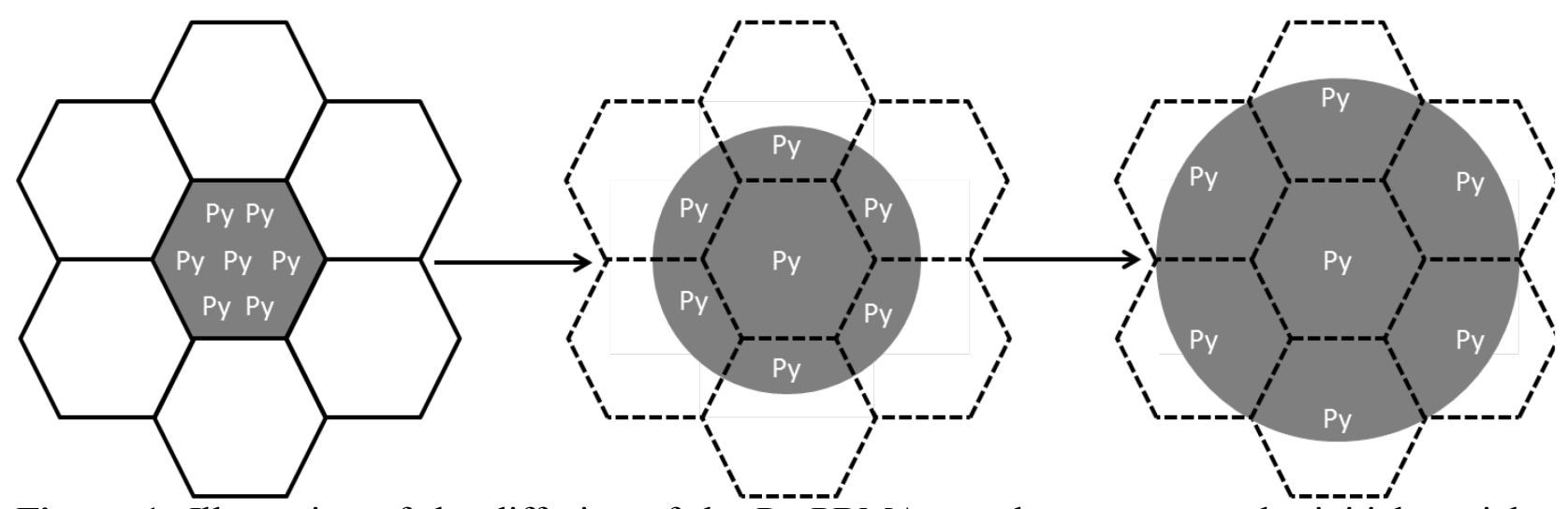

Figure 1: Illustration of the diffusion of the Py-PBMA copolymers across the initial particle boundaries as a function of increasing annealing time.

$$
P y+P y \stackrel{K}{\rightleftharpoons} P y P y
$$

Scheme 1: Equilibrium between pyrene monomers and dimers in a pyrene-labeled film.

Based on Scheme $1, K$ equals $[P y P y] /[P y]^{2}$, where $[P y]$ and $[P y P y]$ are the local concentrations of pyrene monomer and dimer, respectively. IPD occurring in the film at temperatures above the MFT resulted in an increase and a decrease in $[P y]$ and $[P y P y]$, respectively. Rapid cooling of the film to room temperature froze the equilibrium, so that the fluorescence spectrum provided an accurate representation of the concentrations of the pyrene species present after the film had 
been annealed for a set time. Since the $I_{\mathrm{E}} / I_{\mathrm{M}}$ ratio is directly proportional to the local concentration of pyrene dimer over that of the monomer, Equation 2 predicts that the $I_{\mathrm{E}} / I_{\mathrm{M}}$ ratio should be directly proportional to the average local pyrene concentration experienced in the solid-state by an excited pyrene.

$$
\frac{I_{E}}{I_{M}} \propto \frac{[P y P y]}{[P y]}=K[P y]
$$

Since Py-PBMA is randomly labeled with pyrene, there is a finite probability that two consecutive structural units in the chain bear a pyrene label and thus form excimer intramolecularly upon direct excitation. Thus, the local pyrene concentration sensed by an excited pyrene will always be greater than zero, even for an isolated Py-PBMA chain. As a result, the $I_{\mathrm{E}} / I_{\mathrm{M}}$ ratio is always expected to be greater than zero, even for a fully annealed film $\left(t_{\infty}\right)$. Consequently, the $I_{\mathrm{E}} / I_{\mathrm{M}}$ ratio at annealing time $t$ could be determined by integrating the intermolecular and intramolecular contributions of the local pyrene concentration $\left(C_{\mathrm{Py}, \text { inter+intra }}(r, t)\right)$ as a function of distance $r$ from the centre of the pyrene-labeled latex particles. This expression is given in Equation 3, where $\left\langle C_{\mathrm{Py}, \text { inter+intra }}(t)>\right.$ is the average local pyrene concentration and $K^{\prime}$ is a constant that depends on the geometry of the steady-state fluorometer and the equilibrium constant $K$

$$
\frac{I_{E}}{I_{M}}(t)=K^{\prime} \frac{\int_{0}^{\infty}\left(C_{P y, \text { inter }+ \text { intra }}(r, t)\right) \cdot 4 \pi r^{2} d r}{\int_{0}^{\infty} 4 \pi r^{2} d r}=K^{\prime}\left\langle C_{P y, \text { inter }+ \text { intra }}(t)\right\rangle
$$


As depicted in Figure 1, diffusion of the Py-PBMA chains into the surrounding non-labeled particles results in a decrease in the average concentration of pyrene labels that form excimer intermolecularly $\left(<C_{\text {Py,inter }}(t)>\right)$. However since intramolecular excimer formation is the result of pyrene labels held together by the polymer backbone, the average pyrene concentration leading to intramolecular excimer formation $\left(\left\langle C_{\mathrm{Py}, \text { intra }}>\right)\right.$ remains unchanged with time. The result is a decrease in the $I_{\mathrm{E}} / I_{\mathrm{M}}$ ratio as a function of the annealing time due to the decrease in $<C_{\text {Py,inter }}(t)>$. Because the value of $I_{\mathrm{E}} / I_{\mathrm{M}}$ at infinite annealing time $t_{\infty}$ corresponds to an isolated Py-PBMA chain, the fluorescence spectrum acquired for a film at $t_{\infty}$ yields an $I_{\mathrm{E}} / I_{\mathrm{M}}$ ratio corresponding to $<C_{\text {Py,intra }}>$ only, since $<C_{\text {Py,inter }}>$ equals zero at $t_{\infty}$. As shown in Equation 4 , subtracting $I_{\mathrm{E}} / I_{\mathrm{M}}\left(t_{\infty}\right)$ from $I_{\mathrm{E}} / I_{\mathrm{M}}(t)$ yields $<C_{P y, \text { inter }}>$ as a function of $t$.

$$
\frac{I_{E}}{I_{M}}(t)-\frac{I_{E}}{I_{M}}\left(t_{\infty}\right)=K^{\prime} \frac{\int_{0}^{\infty}\left(C_{P y, \text { inter }+ \text { intra }}(r, t)-C_{P y, \text { intra }}\left(r, t_{\infty}\right)\right) \cdot 4 \pi r^{2} d r}{\int_{0}^{\infty} 4 \pi r^{2} d r}=K^{\prime}\left\langle C_{P y, \text { inter }}(t)\right\rangle
$$

As the particles coalesce during film formation, the fraction of mixing between adjacent particles $\left(f_{\mathrm{m}}\right)$ can be determined by calculating the change in $\left\langle C_{\mathrm{Py}}\right.$,inter $>$ as a function of $t$. At time $t_{\mathrm{o}}$, just before heating the film above the MFT, $\left\langle C_{\text {Py,inter }}(t)>\right.$ takes its largest value since all the PyPBMA chains are contained within the labeled particles. As the film is heated above the MFT, $<C_{\text {Py,inter }}(t)>$ begins to decrease and eventually reaches a value of zero when the film has been fully annealed. Taking this into account, $f_{\mathrm{m}}$ is found by calculating the relative changes in $<C_{\text {Py,inter }}>$ over time with respect to $<C_{\text {Py,inter }}\left(t_{0}\right)>$ as described by Equation 5 . By substituting $<\mathrm{C}_{\text {Py,inter }}(t)>$ in the expression with Equation 4, Equation 5 can be simplified such that $f_{\mathrm{m}}$ is expressed solely in terms of the $I_{\mathrm{E}} / I_{\mathrm{M}}(t)$ ratios determined from the steady-state fluorescence measurements. 


$$
f_{m}(t)=\frac{\left\langle C_{P y, \text { inter }}\left(t_{\mathrm{o}}\right)\right\rangle-\left\langle C_{P y, \text { inter }}(t)\right\rangle}{\left\langle C_{P y, \text { inter }}\left(t_{\mathrm{o}}\right)\right\rangle}=\frac{\left(\frac{I_{\mathrm{E}}}{I_{\mathrm{M}}}\right)_{t}-\left(\frac{I_{\mathrm{E}}}{I_{\mathrm{M}}}\right)_{t_{\mathrm{o}}}}{\left(\frac{I_{\mathrm{E}}}{I_{\mathrm{M}}}\right)_{t_{\infty}}-\left(\frac{I_{\mathrm{E}}}{I_{\mathrm{M}}}\right)_{t_{\mathrm{o}}}}
$$

Using the latex mixtures listed in Table 1, films were prepared by depositing ca $0.5 \mathrm{~mL}$ of a mixture of the dispersions onto a quartz plate and allowing it to dry at room temperature overnight under nitrogen. The film was left to dry for such a long time period to ensure the complete removal of water and to minimize any hydroplasticization of the films. ${ }^{27}$ To ensure that no noticeable polymer diffusion occurred during this drying period, the steady-state fluorescence spectrum of a film was measured after three hours of drying, at which point no visible water appeared to remain in the film. The $I_{\mathrm{E}} / I_{\mathrm{M}}$ ratio was calculated to be $0.138 \pm 0.004$ from the steady-state florescence spectrum, and the film was then left to continue drying overnight. The next day, the steady-state fluorescence spectrum was acquired again and the $I_{\mathrm{E}} / I_{\mathrm{M}}$ ratio calculated. Both spectra overlapped, indicating that no noticeable polymer diffusion occurred and that the $I_{\mathrm{E}} / I_{\mathrm{M}}$ ratio remained constant within experimental error at $0.134 \pm 0.003$. The overlapping spectra can be seen in Figure S4.

The steady-state fluorescence spectra were acquired for both Films 1 and 2 (Table 1) as a function of annealing time at nine different annealing temperatures ranging from 75 to $119^{\circ} \mathrm{C}$. The change in the steady-state fluorescence spectra for Film 1, containing the higher molecular weight polymers, annealed at $102{ }^{\circ} \mathrm{C}$ over time can be viewed in Figure 2. Although the fluorescence intensity of the excimer was quite low as compared to that of the monomer, $I_{\mathrm{E}}$ was sufficiently large to observe a significant change in the $I_{\mathrm{E}} / I_{\mathrm{M}}$ ratio over the course of annealing. 
As expected, the $I_{\mathrm{E}} / I_{\mathrm{M}}$ ratio was highest before any annealing occurred, corresponding to an $I_{\mathrm{E}} / I_{\mathrm{M}}$ ratio of $0.134 \pm 0.003$. As the film was annealed and interparticle polymer diffusion (IPD) occurred, the $I_{\mathrm{E}} / I_{\mathrm{M}}$ ratio decreased over time, reaching a value of $0.037 \pm 0.001$ for the homogeneous film. Similar trends in the $I_{\mathrm{E}} / I_{\mathrm{M}}$ ratios as a function of annealing time were found for both films at each annealing temperature. On average, the $I_{\mathrm{E}} / I_{\mathrm{M}}$ ratio for Film 1 decreased from $0.135 \pm 0.003$ before annealing to $0.031 \pm 0.004$ after full annealing. Similarly, the $I_{\mathrm{E}} / I_{\mathrm{M}}$ ratio for Film 2 decreased from $0.119 \pm 0.006$ to $0.024 \pm 0.002$ during the course of annealing at each temperature. The lower $I_{\mathrm{E}} / I_{\mathrm{M}}$ ratios for Film 2 are attributed to the slightly lower pyrene content of Py-PBMA-L2. The $I_{\mathrm{E}} / I_{\mathrm{M}}$ ratios obtained as a function of time are listed in Tables $\mathrm{S} 1-$ S9 for both films.

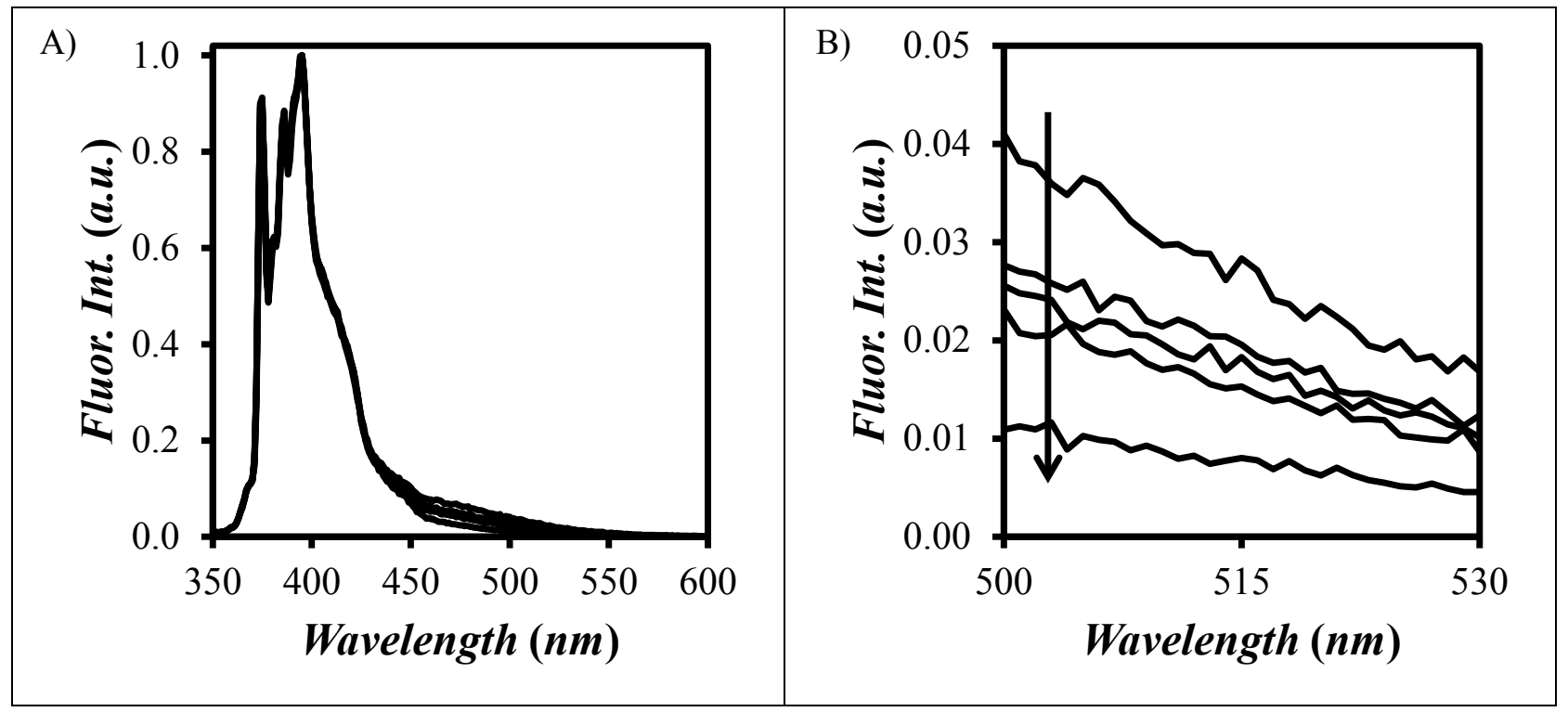

Figure 2: Steady-state fluorescence spectra $\left(\lambda_{\mathrm{ex}}=344 \mathrm{~nm}\right)$ obtained for A) Film 1 containing PyPBMA-L1 annealed at $102{ }^{\circ} \mathrm{C}$, and B) expanded area corresponding to the excimer fluorescence. The curves from top to bottom are for $t_{\mathrm{an}}=0,25,110,560 \mathrm{~min}$, , and a homogeneous film $\left(t_{\mathrm{an}}=\infty\right)$ 
The fraction of mixing of the latex particles $\left(f_{\mathrm{m}}\right)$ was calculated using the $I_{\mathrm{E}} / I_{\mathrm{M}}$ ratios obtained at annealing time $t$ via Equation 5. This equation accounts for the fact that the $I_{\mathrm{E}} / I_{\mathrm{M}}$ ratio for a fully annealed film is greater than zero, as discussed earlier, and that the change in the $I_{\mathrm{E}} / I_{\mathrm{M}}$ ratio is dependent on the local concentration of pyrene forming excimer intermolecularly.

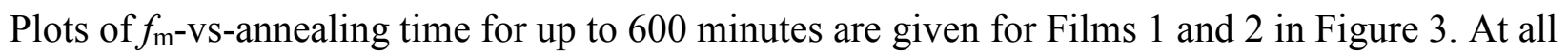
the annealing temperatures, both Films 1 and 2 exhibited a similar behaviour characterized by an initial rapid increase in $f_{\mathrm{m}}$, followed by a slower, much more gradual increase of $f_{\mathrm{m}}$ at longer annealing times. For example, when Film 1 was annealed at $102{ }^{\circ} \mathrm{C}, f_{\mathrm{m}}$ quickly rose to 0.40 after only 25 minutes of annealing, followed by a much more gradual increase to 0.59 after an additional 520 minutes of annealing. This trend matches closely the results obtained in previous FRET studies. ${ }^{3,7-11,28}$ This behaviour was attributed to the rather large dispersity $(\nexists)$ of the polymer present in the film. At early times the diffusion of short polymer chains dominates, resulting in a rapid increase in $f_{\mathrm{m}}$. The short chains quickly reach equilibrium in the film, at which point the diffusion of the larger chains begins to dominate, resulting in a slower but continuous increase in $f_{\mathrm{m}}$. 


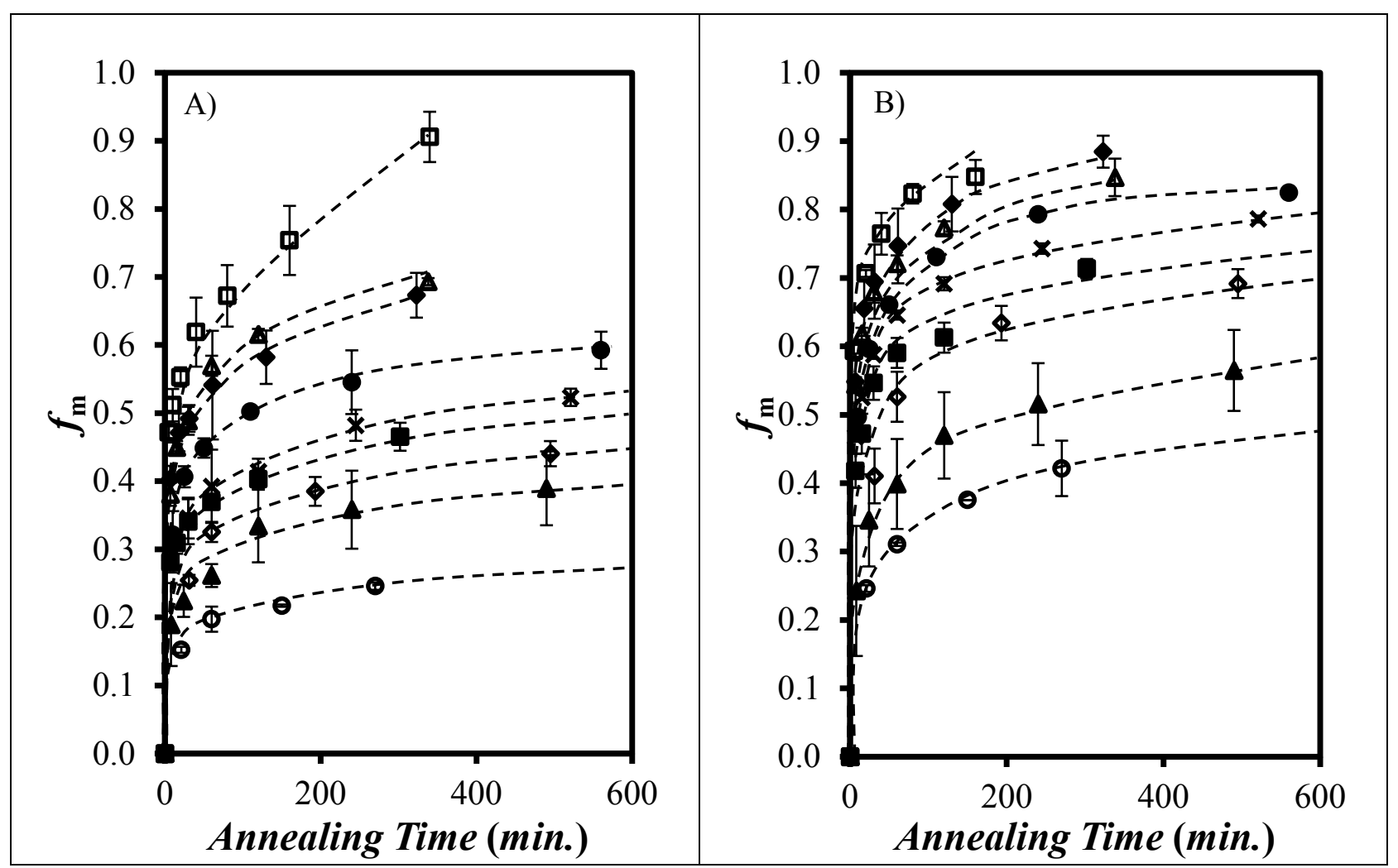

Figure 3: Fraction of mixing for A) Film 1 (Py-PBMA-L1: $\left.M_{w}=820 \mathrm{~kg} \cdot \mathrm{mol}^{-1}, Ð=1.9\right)$ and B)

Film 2 (Py-PBMA-L2: $\left.M_{w}=360 \mathrm{~kg} \cdot \mathrm{mol}^{-1}, Ð=1.8\right) . T_{a n}=119(\boldsymbol{\square}), 112(\bullet), 111(\boldsymbol{\Delta}), 102(\bullet), 98($

^), $94(\boldsymbol{\square}), 88(\bullet), 84(\boldsymbol{\bullet})$, and $75(\mathbf{0}){ }^{\circ} \mathrm{C}$. The dashed lines were only added to guide the eyes.

Values of $f_{\mathrm{m}}$ were obtained for annealing times longer than $600 \mathrm{~min}$. at lower temperatures. They were not included in the plots, but are listed in Tables S1-S9.

The rate at which $f_{\mathrm{m}}$ increased was also strongly dependent on the annealing temperature. A quick inspection of Figure 3 revealed that an increase in annealing temperature yielded a higher $f_{\mathrm{m}}$ after a set annealing time. To help highlight the temperature dependence of $f_{\mathrm{m}}$, Figure 4 displays $f_{\mathrm{m}}$ against annealing time for both Films 1 and 2 at annealing temperatures of 75 and $119^{\circ} \mathrm{C}$, respectively. When Film 1 was annealed at $119^{\circ} \mathrm{C}, f_{\mathrm{m}}$ reached a value of 0.55 after only twenty minutes but when annealed at $75{ }^{\circ} \mathrm{C}$ for the same time, $f_{\mathrm{m}}$ only reached 0.15 . 
Additionally, even after annealing for 19 hours longer at $75^{\circ} \mathrm{C}, f_{\mathrm{m}}$ only increased to 0.36 . Similar trends were observed for Film 2.

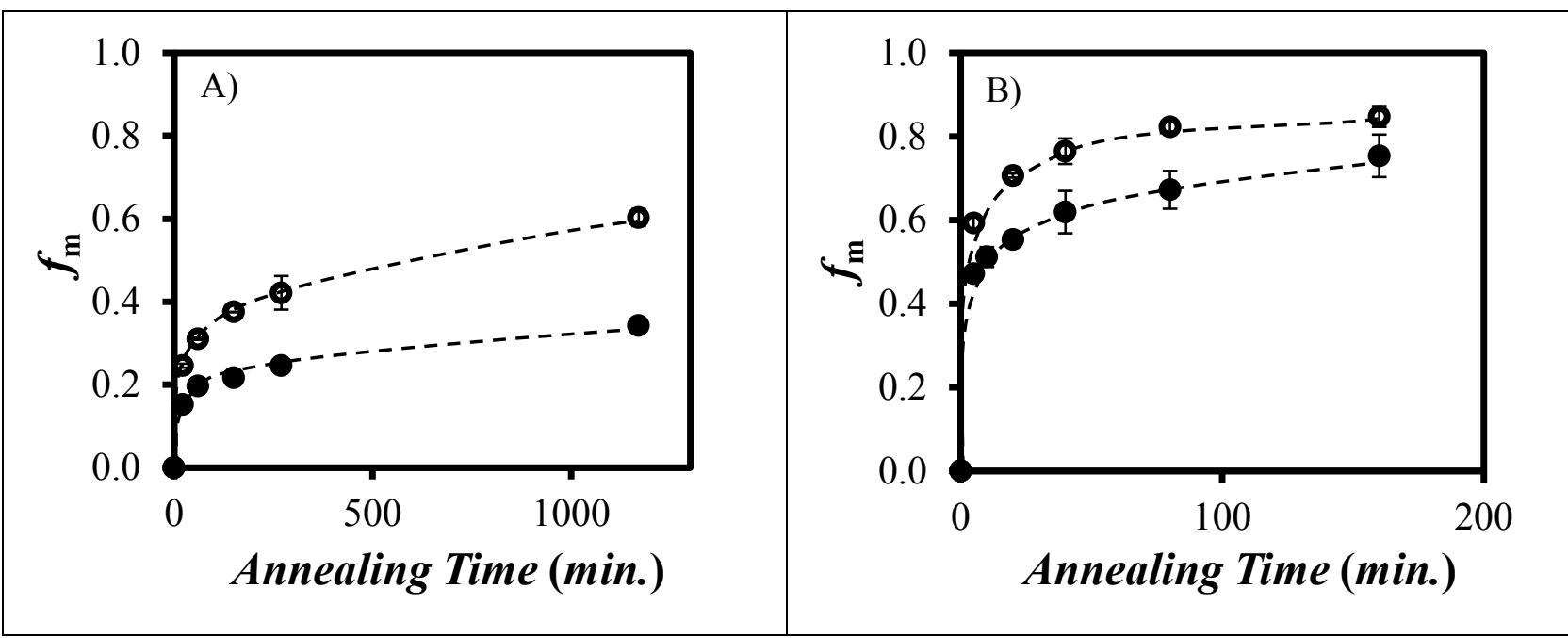

Figure 4: Comparison of the fraction of mixing for (๑) Film 1 and (o) Film 2 at annealing temperatures of A) 75 and B) $119^{\circ} \mathrm{C}$. The dashed lines were only added to guide the eyes.

In addition to the dependence of $f_{\mathrm{m}}$ on temperature, the molecular weight of the polymers constituting the film also affected the rate of film formation. Film 2, prepared from the lower molecular weight polymers, had higher $f_{\mathrm{m}}(t)$ values in Figure 4 as compared to those obtained for Film 1 at a same annealing temperature. For comparison purposes, both Films 1 and 2 were annealed at $75^{\circ} \mathrm{C}$ for 19.5 hours, corresponding to 1,170 minutes in Figure $4 \mathrm{~A}$. Film $1\left(M_{w}=\right.$ $\left.820 \mathrm{~kg} \cdot \mathrm{mol}^{-1}\right)$ reached an $f_{\mathrm{m}}$ value of 0.34 , whereas the particles in Film $2\left(M_{w}=360 \mathrm{~kg} \cdot \mathrm{mol}^{-1}\right)$ mixed nearly twice as much, resulting in an $f_{\mathrm{m}}$ value of 0.60 . This difference in $f_{\mathrm{m}}(t)$ between the two films was most prominent at lower annealing temperatures. When the two films were annealed at $119{ }^{\circ} \mathrm{C}$, the $f_{\mathrm{m}}$ values were found to be much closer with values of 0.75 and 0.84 for Films 1 and 2 after 160 minutes, respectively. 
Polymer Diffusion: To obtain a more quantitative measure of film formation, the apparent diffusion coefficient $(D)$ of the pyrene-labeled polymer chains was determined. For consistency with previous studies, ${ }^{3,711,28}$ a Fickian model of molecules diffusing out of a sphere with radius $R$ equal to the particle radius was used. This model predicts that the concentration profile of the polymer chains bearing the pyrene pendants as a function of distance $r$ from the particle centre at annealing time $t$ is given by Equation 6, where $C_{o}$ is the initial concentration within the labeled particles. ${ }^{29}$

$$
C(r, t)=\frac{C_{\mathrm{o}}}{2}\left[\operatorname{erf}\left(\frac{R+r}{2(D t)^{\frac{1}{2}}}\right)+\operatorname{erf}\left(\frac{R-r}{2(D t)^{\frac{1}{2}}}\right)\right]-\frac{C_{o}}{r}\left(\frac{D t}{\pi}\right)^{\frac{1}{2}}\left[\exp \left(-\frac{(R-r)^{2}}{4 D t}\right)-\exp \left(-\frac{(R+r)^{2}}{4 D t}\right)\right]
$$

The mass fraction of polymer $\left(f_{\mathrm{m}}\right)$ having diffused across the initial particle interface at time $t$ is equal to the mass of polymer $\left(M_{\mathrm{t}}\right)$ having crossed the interface divided by the total mass of polymer $\left(M_{\infty}\right)$ that could ever diffuse across the particle interface. The total mass is given by $4 / 3 \pi \mathrm{R}^{3} \mathrm{C}_{\mathrm{o}}$, and the expression for $M_{\mathrm{t}}$ is provided in Equation 7.

$$
M_{t}=M_{\infty}-\int_{0}^{R} C(r, t) 4 \pi r^{2} d r
$$

These equations can be combined into Equation 8 to yield the calculated fraction of mixing at any annealing time. 


$$
f_{m}(t)=1-\frac{\int_{0}^{R} C(r, t) 4 \pi r^{2} d r}{\frac{4}{3} \pi R^{3} C_{o}}
$$

Since the radius of the particles is known, the only unknown parameter in Equation 8 is the diffusion coefficient $D$ for the Py-PBMA chains diffusing out of the pyrene-labeled latex. By equating the experimental fraction $\left(f_{\mathrm{m}}\right)$ obtained in Equation 5 with the calculated $f_{\mathrm{m}}$ value in Equation 8, the diffusion coefficient can be optimized via numerical integration of Equation 6. Figure 5 displays the diffusion coefficients retrieved for both Films 1 and 2 over the different annealing temperatures as a function of time and $f_{\mathrm{m}}$. The annealing times $t_{0}$ and $t_{\infty}$ were omitted from these diffusion calculations, since they were used as references in calculating the experimental $f_{\mathrm{m}}$ values. Similarly to the trends obtained for $f_{\mathrm{m}}$ in Figure 3, higher annealing temperatures resulted in larger $D$ values. At higher temperatures, increased thermal energy resulted in more rapid Brownian motions for the polymer chains and a larger measured diffusion coefficient. In addition, when $D$ was compared between Films 1 and 2 for the same annealing temperature, $D$ was larger for Film 2. Since Film 2 contained chains with a significantly lower molecular weight, this result was expected because shorter chains diffuse more quickly than larger ones. 


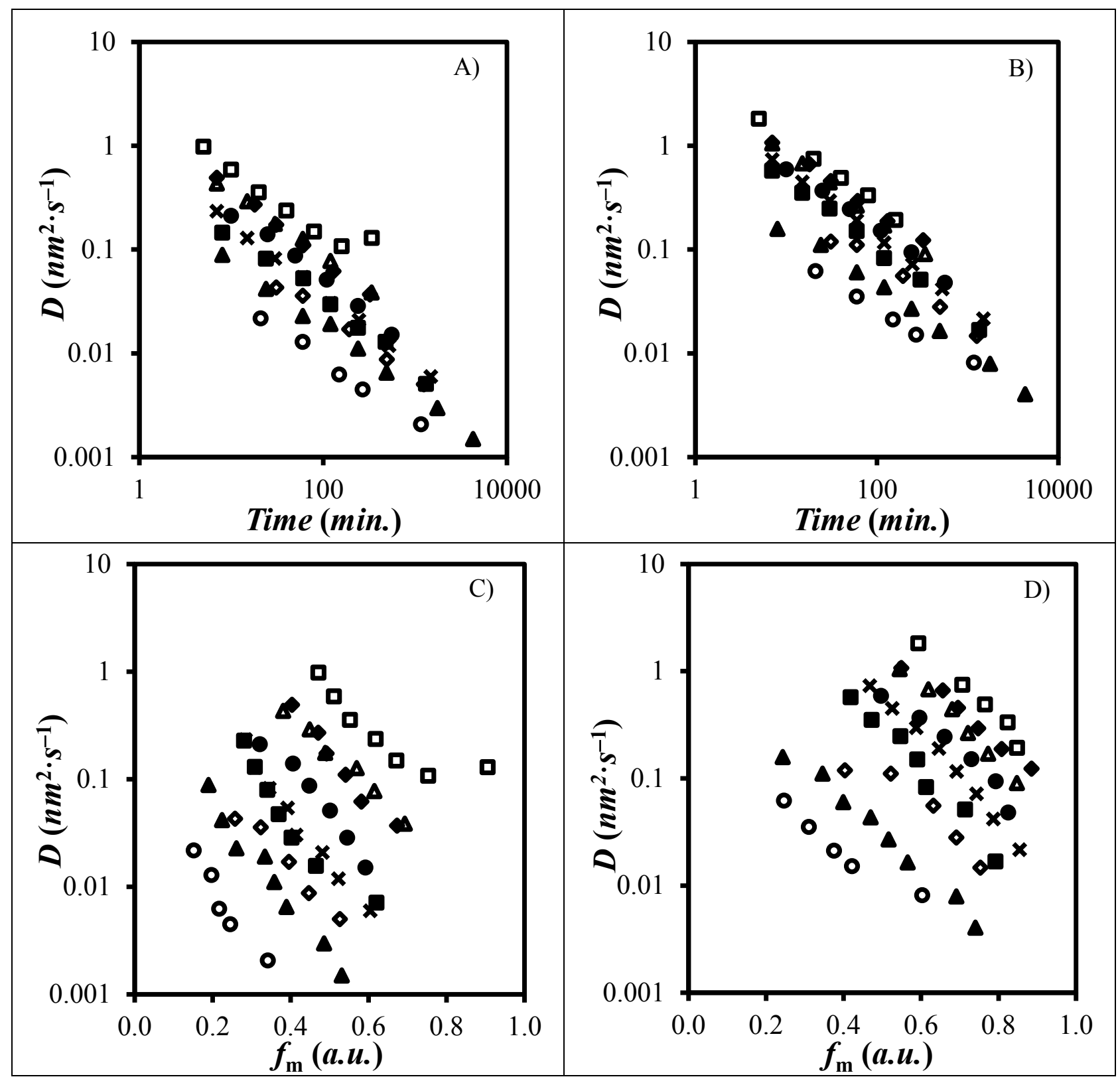

Figure 5: Plot of the apparent diffusion coefficients as a function of annealing time for (A, C)

Film 1 and $(\mathrm{B}, \mathrm{D})$ Film 2 as a function of $(\mathrm{A}, \mathrm{B})$ annealing time and $(\mathrm{C}, \mathrm{D})$ fraction of mixing. From top to bottom $T_{a n}=119(\mathbf{\square}), 112(\bullet), 111(\boldsymbol{\Delta}), 102(\bullet), 98(\boldsymbol{*}), 94(\boldsymbol{\bullet}), 88(\bullet), 84(\boldsymbol{\Delta})$, and 75( o) ${ }^{\circ} \mathrm{C}$.

One of the most apparent trends in the $D$-vs- $t$ plots was the rapid decrease in $D$ with increasing time, a trend that has been observed in previous studies ${ }^{8,28,30,31}$ and was attributed to 
the dispersity of the polymer chains. Since $D$ represents all the polymer chains present in the film, both large and small, diffusion is dominated by the shorter chains at early times, resulting in a large $D$ value. As time passes, diffusion of the larger chains is being captured by the $I_{\mathrm{E}} / I_{\mathrm{M}}$ ratio, resulting in a decrease in $D$ over time. In addition to the effect of dispersity of the PyPBMA chains on the diffusion coefficient, the decrease in $D$ over time might also be a result of strain relaxation of the polymer chains near the particle surface. ${ }^{4}$ Before annealing occurs all the polymer chains are confined to individual particles, with the chains closer to the particle surface having a restricted number of configurations, since the particle boundary limits their configurational space. These confined chains are expected to diffuse more quickly at early times to reduce this configurational strain, resulting in a $\operatorname{larger} D$ value at early times.

Temperature Dependence: To push our analysis one step further, the temperature dependence of $D$ was determined according to a procedure developed by the Winnik Group to probe IPD in latex films. ${ }^{3,7,8,9,10,11,28}$ To begin the analysis, the WLF equation is modified in such a way that the shift factors can be found in terms of the diffusion coefficients as shown in Equation 9, where $D_{o}$ is the diffusion coefficient at the reference temperature $T_{0}$ and $c_{1}$ and $c_{2}$ are the WLF parameters. The reference temperature selected is arbitrary and can be changed easily.

$$
\log \left(a_{T}\right)=\log \left(\frac{D_{o} T}{D T_{o}}\right)=\frac{-c_{1} \cdot\left(T-T_{o}\right)}{c_{2}+T-T_{o}}
$$

Using the results of Equation 9, the apparent activation energy of diffusion $E_{\mathrm{a}}$ for the polymer chains is determined using an Arrhenius plot via Equation 10, where $R$ is the universal gas constant. ${ }^{32}$ 


$$
E_{a}=R \frac{d \ln \left(a_{T}\right)}{d\left(T^{-1}\right)}=R \cdot \ln (10) \cdot \frac{c_{1} \cdot c_{2} \cdot T^{2}}{\left(c_{2}+T-T_{o}\right)^{2}}
$$

The viscous flow of polymer chains can be described by the Arrhenius equation shown in Equation 11, where $A$ is a constant.

$$
\eta=A e^{\frac{E_{a}}{R T}}
$$

Using the Stokes-Einstein equation, the viscosity in Equation 11 can be rewritten in terms of the diffusion coefficient for the polymer chains as shown in Equation 12. A plot of $\ln (D / T)$ against $1 / T$ should be linear with a slope equal to $E_{\mathrm{a}} / R$, and therefore $E_{\mathrm{a}}$ can be determined without having to calculate the shift factors.

$$
\eta \propto \frac{D}{T} \propto e^{\frac{E_{a}}{R T}}
$$

Over a limited temperature range, the temperature term in $\ln (D / T)$ becomes insignificant and a plot of $\log (D)$ vs $1 / T$ should be linear, with a slope equal to $E_{\mathrm{a}} / R$. Previous FRET studies by Winnik et al. have shown that plots of $\log (D)$-vs-1/T are indeed linear for PBMA, as long as the plotted $D$ values correspond to a same fraction of mixing over the temperature interval considered. ${ }^{3,8,11}$ The reliability of the $\log (D)$-vs-1/T plot, and thus the accuracy of the $E_{\text {a }}$ value obtained from the slope, has been found to depend critically on the closeness of the $f_{\mathrm{m}}$ values used to select pairs of $D$ and $T$ values. Despite the large number of data points collected (see 
Figure 5), the selection of identical $f_{\mathrm{m}}$ values was a significant limitation in this analysis, since there were very few temperatures where the $D$ values retrieved corresponded to a same $f_{\mathrm{m}}$ value. Figure 6 compares the $\log (D)$ vs $1 / T$ plots obtained for both Films 1 and 2 with a PBMA film probed by FRET. ${ }^{8}$ For both films, a straight line was obtained whose slope yielded $E_{a}$ values of $180 \pm 8$ and $170 \pm 10 \mathrm{~kJ} \cdot \mathrm{mol}^{-1}$ for Films 1 and 2, respectively. These values were similar to, but slightly larger than the $E_{a}$ values of $155 \mathrm{~kJ} \cdot \mathrm{mol}^{-1}$ determined for PBMA with $M_{\mathrm{w}}=370 \mathrm{~kg} \cdot \mathrm{mol}^{-1}$ in the bulk at $100{ }^{\circ} \mathrm{C}$ by dynamic mechanical analysis (DMA)..$^{33,34}$

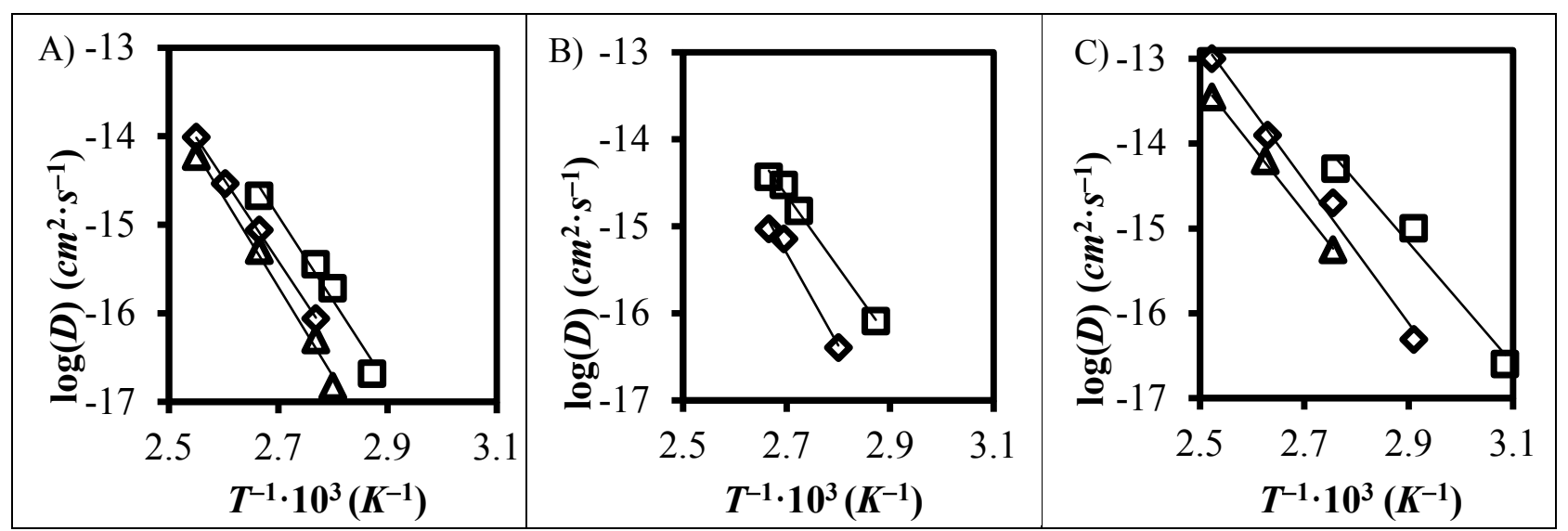

Figure 6: Arrhenius plots used to find the activation energy of the diffusion coefficient for A)

Film $1\left(M_{w}=820 \mathrm{~kg} \cdot \mathrm{mol}^{-1}, \oslash=1.9, E_{a}=180 \pm 8 \mathrm{~kJ} \cdot \mathrm{mol}^{-1}\right) ; f_{\mathrm{m}}$ equal to (ㅁ) $0.32,(\bullet) 0.45$, and

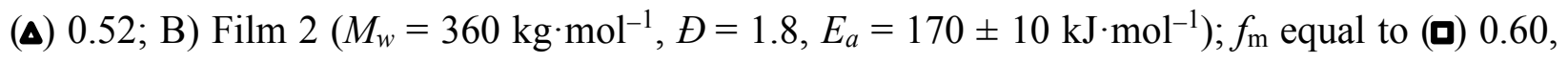
and (४) 0.75; and C) a PBMA film using FRET measurements $\left(M_{w}=420 \mathrm{~kg} \cdot \mathrm{mol}^{-1}, D=5.0, E_{a}=\right.$ $\left.159 \mathrm{~kJ} \cdot \mathrm{mol}^{-1}\right) ; f_{\mathrm{m}}$ equal to (ם) $0.38,(\bullet) 0.90$, and (ه) $0.95 .{ }^{8}$ The fraction of mixing was constant $( \pm 0.01)$ for each series.

The $E_{\mathrm{a}}$ values obtained by pyrene excimer fluorescence (PEF) matched more closely the $E_{\mathrm{a}}$ values reported (without error estimates) of 163 and $159 \mathrm{~kJ} \cdot \mathrm{mol}^{-1}$ for PBMA by FRET 
measurements, corresponding to polymers with $M_{\mathrm{w}}=600$ and $420 \mathrm{~kg} \cdot \mathrm{mol}^{-1}$, respectively. ${ }^{3,8}$ Within error limits, the $E_{\mathrm{a}}$ value of $170 \pm 10 \mathrm{~kJ} \cdot \mathrm{mol}^{-1}$ found for Film $2\left(\mathrm{M}_{\mathrm{w}}=360 \mathrm{~kg} \cdot \mathrm{mol}^{-1}\right)$ by PEF is consistent with the values found using FRET measurements. The $E_{\text {a }}$ values reported in the literature for DMA and FRET studies were plotted as a function of $M_{\mathrm{w}}$ in Figure S5. The trend obtained in Figure S5 suggests that an increase in $M_{\mathrm{w}}$ leads to higher $E_{\mathrm{a}}$ values. Consequently, the higher $E_{\mathrm{a}}$ value found for Film 1 in Figure S5 may be due to the significantly larger $M_{\mathrm{w}}$ value of $820 \mathrm{~kg} \cdot \mathrm{mol}^{-1}$.

Typically, the next step in the Winnik analysis would be to determine the WLF parameters from the shift factors retrieved using Equation 9 for $D$ values corresponding to a same $f_{\mathrm{m}}$. However, due to the severe limitations of using $D$ values as a function of temperature that would correspond to a same fraction of mixing, there were not enough data points in Figure 5 to continue the analysis based on the limited number of shift factors calculated using Equation 9. To obtain more accurate results, a less restrictive method was implemented to calculate the shift factors in a $D$-vs- $f_{\mathrm{m}}$ plot. Similarly to the method of Winnik, the diffusion coefficients were shifted to a reference temperature using a shift factor $\left(a_{\mathrm{T}}\right)$ as defined in Equation 13. However, instead of calculating $a_{\mathrm{T}}$ using $D$ values as a function of temperature obtained for a same $f_{\mathrm{m}}$ value, $a_{\mathrm{T}}$ was found by shifting the entire diffusion profile along the diffusion axis in Figure 5 at a given temperature $T$ to the reference temperature $T_{\mathrm{o}}$, following a procedure similar to that of the WLF method. ${ }^{33,34,35}$ This adapted procedure allowed the retrieval of the same quantitative information from a plot of $\log (D)$-vs- $f_{\mathrm{m}}$ as done by Winnik, but without the restriction of using $D$ values obtained for a same fraction of mixing.

Using Equation 13, a plot of $\log (D)$-vs- $f_{\mathrm{m}}$ at an annealing temperature $T$ was shifted by $a_{\mathrm{T}}$ such that the curve overlapped with the $D_{\mathrm{o}}$ values at the reference temperature $T_{\mathrm{o}}$. A reference 
temperature of $102{ }^{\circ} \mathrm{C}$ was used since it is close to $100{ }^{\circ} \mathrm{C}$, the temperature at which the properties of PBMA have been reported. ${ }^{33,34}$

$$
D_{o}=\frac{D T_{o}}{T} a_{T}
$$

A least squares method was applied to ensure that an optimal $a_{T}$ was found. This resulted in a smooth and relatively tight master curve for each film, as shown in Figures 7A and $\mathrm{B}$. The shift factors and their corresponding $R^{2}$ values are provided in Table $\mathrm{S} 10$. The $R^{2}$ values were all close to unity, indicating good fits.

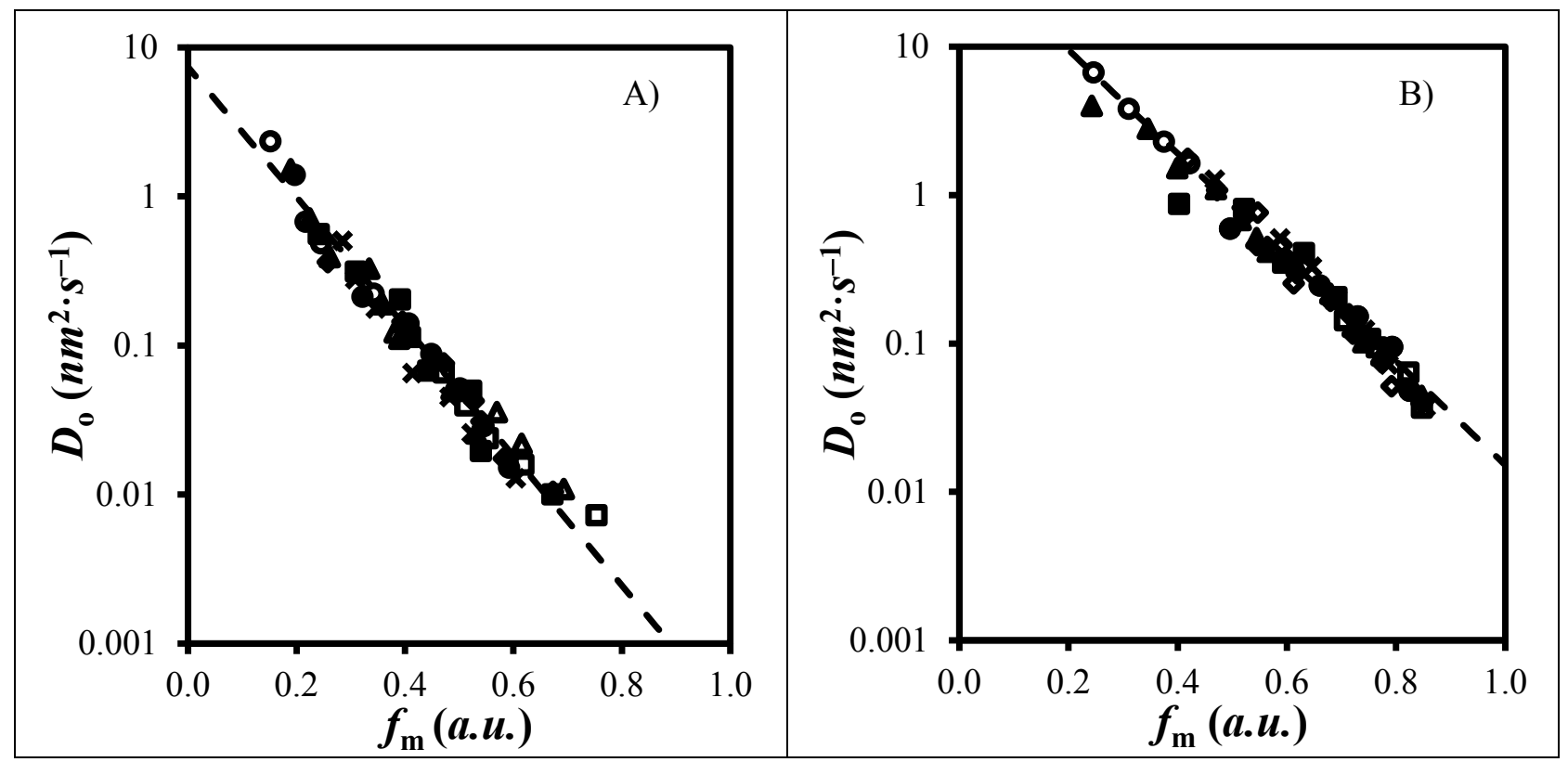

Figure 7: Master curves for the temperature-corrected diffusion coefficients plotted as a function

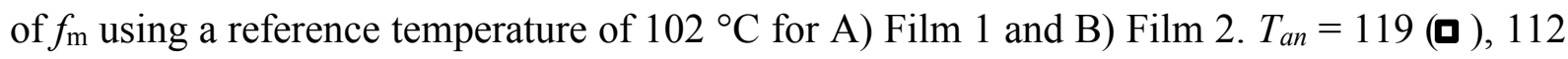
), $111(\boldsymbol{\Delta}), 102(\bullet), 98(\star), 94(\bullet) 88(\bullet), 84(\bullet \quad)$, and $75(\bullet \quad){ }^{\circ} \mathrm{C}$. 
The shift factors obtained using Equation 11 should match those found using the procedure introduced by Winnik et al. In turn, analysis of the $a_{\mathrm{T}}$ values retrieved from Equation 11 should yield $E_{\text {a }}$ values comparable with those reported earlier. From Equation 10, a plot of $\ln \left(a_{\mathrm{T}}\right)$-vs- $1 / T$ should yield a straight line with a slope equal to $E_{\mathrm{a}} / R$. For both Films 1 and 2, a linear trend was observed in Figure 8 with slopes corresponding to $E_{\text {a values of }} 179 \pm 7$ and 170 $\pm 12 \mathrm{~kJ} \cdot \mathrm{mol}^{-1}$ for Films 1 and 2, respectively. As expected, the $E_{\mathrm{a}}$ were very close to the values of $180 \pm 8$ and $170 \pm 10 \mathrm{~kJ} \cdot \mathrm{mol}^{-1}$ for Films 1 and 2, respectively, found earlier using the data of Figure 6.

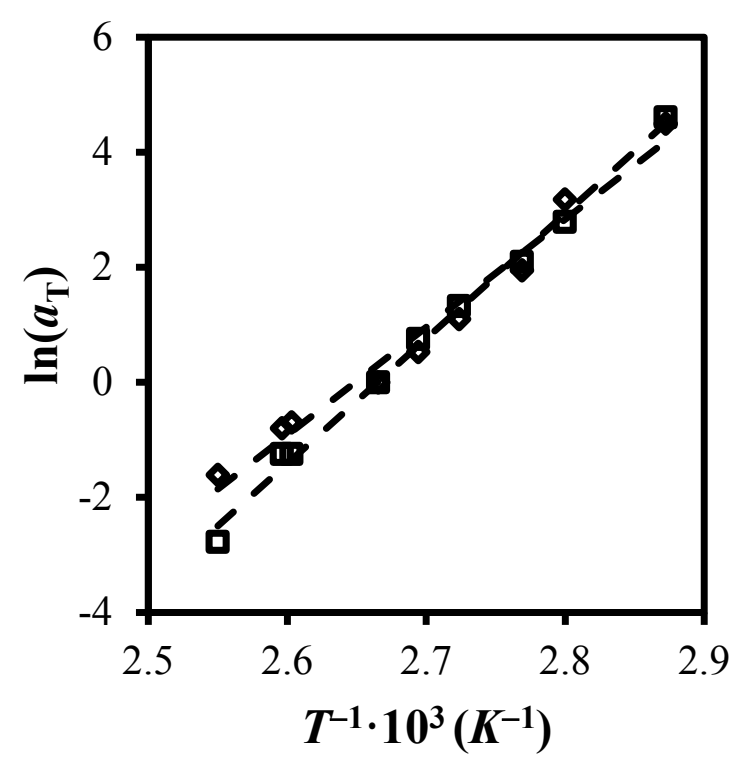

Figure 8: Arrhenius plot of $\ln \left(a_{\mathrm{T}}\right)$ as a function of $1 / T$ for Film $1(\mathbf{(})$ and Film $2(\bullet)$.

Following the procedure developed by Winnik et al., the shift factors were then used in conjunction with the WLF equation given in Equation 10 to find the $c_{1}$ and $c_{2}$ values for PBMA 
in both films. By rearranging the WLF equation as shown in Equation 12, a plot of $\left(T-T_{\mathrm{o}}\right) / \log \left(a_{\mathrm{T}}\right)$ against $T-T_{\mathrm{o}}$ should yield a straight line with slope and intercept equal to $-1 / c_{1}$ and $-c_{2} / c_{1}$, respectively.

$$
\frac{T-T_{o}}{\log \left(a_{T}\right)}=\frac{-\left(T-T_{o}\right)}{c_{1}}-\frac{c_{2}}{c_{1}}
$$

Film 1, prepared from the higher molecular weight polymers, yielded the linear $\left(T-T_{\mathrm{o}}\right) / \log \left(a_{\mathrm{T}}\right)$ vs- $\left(T-T_{\mathrm{o}}\right)$ plot shown in Figure 9.

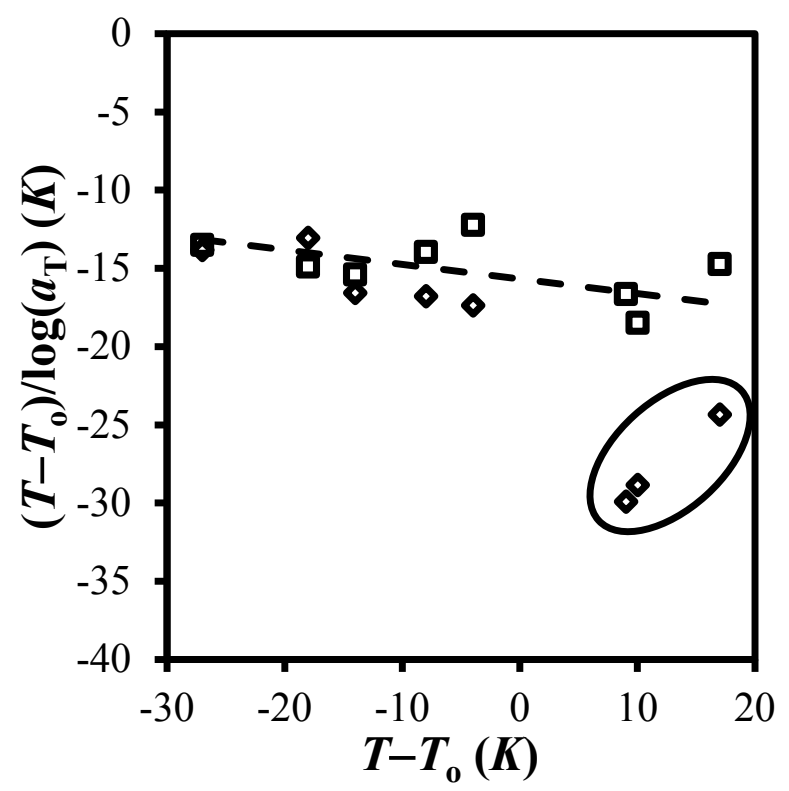

Figure 9: Plot of the linearized WLF Equation $10\left(T_{\mathrm{o}}=102{ }^{\circ} \mathrm{C}\right)$, using the shift factors to extract the $c_{1}$ and $c_{2}$ parameters for Film 1 (ם) and Film $2(\bullet)$. The slope and intercept for the dashed line are -0.09 and $-15.7 \mathrm{~K}$, respectively. The circled area indicates data points that disobey WLF behaviour. 
The $c_{1}$ and $c_{2}$ values were found to equal $11 \pm 2$ and $170 \pm 30 \mathrm{~K}$, respectively. These are comparable to the $c_{1}$ and $c_{2}$ values reported previously (without error bars) for PBMA in the bulk at $100{ }^{\circ} \mathrm{C}$ by dynamic mechanical analysis, with $c_{1}=9.7$ and $c_{2}=169.6 \mathrm{~K} \cdot{ }^{33}$ Film 2 followed the same linear trend as Film 1 up to the reference temperature of $102^{\circ} \mathrm{C}$, but above this temperature significant deviation was observed.

One possible explanation for the behaviour observed for Film 2 at high annealing temperatures might lie with the molecular weight difference between the polymers in the two films. Typically, the WLF equation is valid for temperatures ranging from $T_{\mathrm{g}}$ to $T_{\mathrm{g}}+\Delta T$, where $\Delta T$ ranges between 50 and $100 \mathrm{~K}$ depending on the polymer. ${ }^{32}$ This temperature range corresponds to the rubbery plateau region. As the temperature increases further the polymer enters the viscous flow region, where the WLF equation no longer applies. Polymers with higher molecular weights exhibit an extended rubbery plateau region as compared with those with lower molecular weights. In this case it may be that Film 1, with its higher molecular weight, follows WLF behaviour up to $119^{\circ} \mathrm{C}$ due to an extended rubbery plateau. The polymers in Film 2, with a much lower molecular weight, may have a reduced temperature range where WLF behaviour is obeyed.

Lastly, the $c_{1}$ and $c_{2}$ parameters found above were employed to calculate the activation energy at $102{ }^{\circ} \mathrm{C}$ using Equation 10 and yielded an $E_{\text {a }}$ value of $172 \pm 38 \mathrm{~kJ} \cdot \mathrm{mol}^{-1}$. This activation energy matches the values of $179 \pm 7$ and $170 \pm 12 \mathrm{~kJ} \cdot \mathrm{mol}^{-1}$ found above for Films 1 and 2, respectively, showing that the results obtained by PEF analysis are internally consistent with one another. 


\section{Advantages Associated with the Application of Pyrene Excimer Fluorescence to Study}

Latex Film Formation: The above results demonstrate that the method based on PEF introduced in this report provides not only the same quantitative information on film formation as experiments based on FRET, but does so in a much less restrictive and simpler manner. Since PEF occurs upon direct contact between two pyrene labels, it is a direct representation of the local ground-state pyrene concentration experienced by an excited pyrene, and the average local pyrene concentration in the film is obtained from the measurement of a fluorescence intensity ratio, namely the $I_{\mathrm{E}} / I_{\mathrm{M}}$ ratio, from the steady-state fluorescence spectra. In contrast, when timeresolved fluorescence is used as in FRET analysis, not only does data acquisition takes significantly longer, but the resulting fluorescence decays must be fitted with an appropriate model before useful parameters can be extracted. In addition, PEF is mathematically much simpler than FRET since PEF occurs only upon direct contact between pyrene labels, whereas the efficiency of FRET depends heavily on the distance separating the donor-acceptor pairs. By far the main advantage of this new method based on PEF is that only one batch of fluorescentlylabeled latex particles must be prepared. Since the unlabeled particles do not need to be modified in any way, the pyrene-labeled particles can be used to directly probe film formation in an offthe-shelf latex. Furthermore, since excimer formation is mathematically much simpler to handle than FRET, and since the study requires that only one latex be labeled, this method allows for several interesting studies that would have been difficult to conduct using earlier methods. One of the most interesting examples is the study of film formation between latex particles having asymmetric properties, such as particles with different sizes. 


\section{CONCLUSIONS}

The coalescence of PBMA latex particles into a film was quantitatively probed using PEF. Two films were studied, one prepared with a PBMA sample having a relatively high $M_{w}=820$ $\mathrm{kg} \cdot \mathrm{mol}^{-1}$, and the other with a polymer having a lower $M_{w}=360 \mathrm{~kg} \cdot \mathrm{mol}^{-1}$. The films were cast from a mixture consisting of $95 \mathrm{wt} \%$ of unlabeled PBMA latex and $5 \mathrm{wt} \%$ of a pyrene-labeled latex. The fraction of mixing between the latex particles was obtained as a function of annealing time using steady-state fluorescence at nine annealing temperatures ranging from 75 to $119{ }^{\circ} \mathrm{C}$. In agreement with previous studies, ${ }^{3,7-11,28}$ increasing the annealing temperature for a given polymer sample or decreasing the molecular weight of the polymer at the same annealing temperature led to an increase in $f_{\mathrm{m}}$. A more quantitative analysis was conducted next by determining the diffusion coefficients $(D)$ for the polymer chains in the film. $D$ was found to increase with decreasing molecular weight and for increasing annealing temperatures. The temperature dependence of $D$ was characterized following a method developed by Winnik et al. to probe film formation by FRET. Using $D$ values as a function of temperature at constant $f_{\mathrm{m}}, E_{a}$ $=180 \pm 8$ and $170 \pm 10 \mathrm{~kJ} \cdot \mathrm{mol}^{-1}$ were found, which are close to the $E_{a}$ values previously determined by both DMA and FRET. The implementation of a method generalizing the procedure introduced by Winnik et al. enabled the determination of the shift factors for the diffusion coefficients using $D$-vs- $f_{\mathrm{m}}$ plots. The shift factors were fitted with an Arrhenius-type equation to find the apparent activation energy for diffusion. The $E_{a}$ values found were $179 \pm 7$ and $170 \pm 12 \mathrm{~kJ} \cdot \mathrm{mol}^{-1}$ for Films 1 and 2 , respectively, in relatively good agreement with those obtained by the method of Winnik et al. Next, a linearized plot of the WLF equation was used to determine the $c_{1}$ and $c_{2}$ parameters, found to equal $11 \pm 2$ and $170 \pm 30 \mathrm{~K}$, respectively. These were again in good agreement with values previously determined for PBMA by DMA. Lastly, 
using the $c_{1}$ and $c_{2}$ values, $E_{\mathrm{a}}$ value was calculated to be $172 \pm 37 \mathrm{~kJ} \cdot \mathrm{mol}^{-1}$, which matched the $E_{\mathrm{a}}$ found using an Arrhenius plot of the shift factors.

\section{ACKNOWLEDGEMENTS}

The authors thank BASF and NSERC for generous funding. They are also indebted to Dr. James W. Taylor from BASF for numerous informative discussions.

\section{REFERENCES}

1. Gauthier, C.; Guyot, A.; Perez, J.; Sindt, O. Film Formation and Mechanical Behavior of Polymer Laticies. Film Formation in Waterborne Coatings, American Chemical Society: Washington, DC 1996, Chapter 10, pp 163-178.

2. Eckersley, S. T.; Rudin, A. Film Formation of Acrylic Copolymer Laticies: A Model of Stage II Film Formation. Film Formation in Waterborne Coatings, American Chemical Society: Washington, DC 1996, Chapter 1, pp 2-21.

3. Wang, Y.; Winnik, M. A. Polymer Diffusion Across Interfaces in Latex Films. J. Phys. Chem. 1993, 97, 2507-2515.

4. Kim, K. D.; Sperling, L. H.; Klein, A.; Wignall, G. D. Characterization of Film Formation from Direct Multi-emulsified Polystyrene Latex Particles via SANS. Macromolecules 1993, 26, 4624-4631.

5. Hahn, K.; Ley, G; Schuller, H.; Obethür, R. On Particle Coalescence in Latex Films. Colloid \& Polym. Sci. 1986, 264, 1092-1096. 
6. Hahn, K.; Ley, G.; Obethür, R. On Particle Coalescence in Latex Films (II). Colloid \& Polym. Sci. 1988, 226, 631-639.

7. Pekcan, Ö.; Winnik, M. A. Fluorescence Studies of Coalescence and Film Formation in Poly(methyl methacrylate) Nonaqueous Dispersion Particles. Macromolecules 1990, 23, 2673-2678.

8. Zhao, C.; Wang, Y.; Hruska, Z.; Winnik, M. A. Molecular Aspects of Latex Film Formation: An Energy-Transfer Study. Macromolecules 1990, 23, 4082-4087.

9. Wang, Y.; Winnik, M. A. Energy-Transfer Study of Polymer Diffusion in Melt-Pressed Films of Poly(methyl methacrylate). Macromolecules 1993, 26, 3147-3150.

10. Farinha, J. P. S.; Martinho, J. M. G.; Yekta, A.; Winnik, M. A. Direct Nonradiative Energy Transfer in Polymer Interphases: Fluorescence Decay Functions from Concentration Profiles Generated by Fickian Diffusion. Macromolecules 1995, 28, 6084-6088.

11. Ye, X.; Farinha, J. P. S.; Oh, J. K.; Winnik, M. A.; Wu, C. Polymer Diffusion in PBMA Latex Films Using a Polymerizable Benzophenone Derivative as an Energy Transfer Acceptor. Macromolecules 2003, 36, 8749-8760.

12 . Farinha, J. P. S.; Wu, J.; Winnik, M. A.; Farwaha, R.; Rademacher, J. Polymer Diffusion in Gel-Containing Poly(vinyl acetate-co-dibutyl maleate) Latex Films. Macromolecules 2005, $38,4393-4402$.

13. Liu, Y.; Haley, J. C.; Deng, K.; Lau, W.; Winnik, M. A. Effect of Polymer Composition on Copolymer Diffusion in Poly(butyl acrylate-co-methyl methacrylate) Latex Films. Macromolecules 2007, 40, 6422-6431. 
14. Liu, Y.; Schroeder, W. F.; Haley, J. C.; Lau, W.; Winnik, M. A. Effect of Branching on Polymer Diffusion in Branched Poly(butyl methacrylate) Latex Films. Macromolecules 2008, 41, 9104-9111.

15. Haley, J. C.; Liu, Y.; Winnik, M. A.; Demmer, D.; Haslett, T.; Lau, W. Tracking Polymer Diffusion in a Wet Latex Film with Fluorescence Resonance Energy Transfer. Rev. Sci. Intruments 2007, 78, 084101.

16. Haley, J. C.; Liu, Y.; Winnik, M. A.; Lau, W. The Onset of Polymer Diffusion in a Drying Acrylate Latex: How Water Initially Retards Coalescence but Ultimately Enhances Diffusion. J. Coat. Technol. Res. 2008, 5, 157-168.

17. Soleimani, M.; Haley, J. C.; Lau, W.; Winnik, M. A.; Effect of Hydroplasticization on Polymer Diffusion in Poly(butyl acrylate-co-methyl methacrylate) and Poly(2-ethylhexyl acrylate-co-tert-butyl methacrylate) Latex Films. Macromolecules 2010, 43, 975-985.

18. Soleimani, M.; Khan, S.; Mendenhall, D.; Lau, W.; Winnik, M. A. Effect of Molecular Weight Distribution on Polymer Diffusion During Film Formation of Two-Component High-/Low-Molecular Weight Latex Particles. Polymer 2012, 53, 2652-2663.

19. Schroeder, W. F.; Liu, Y.; Tomba, J. P.; Soleimani, M.; Lau, W. ; Winnik, M. A. Influence of Ethylene Glycol and Propylene Glycol on Polymer Diffusion in Poly(butyl acrylate-comethyl methacrylate) Latex Films. J. Phys. Chem. B 2010, 114, 3085-3094.

20. Schroeder, W. F.; Liu, Y.; Tomba, J. P.; Soleimani, M.; Lau, W. ; Winnik, M. A. Effect of a Coalescing Aid on the Earliest Stages of Polymer Diffusion in Poly(butyl acrylate-co-methyl methacrylate) Latex Films. Polymer 2011, 52, 3984-3993. 
21. Pohl, K.; Adams, J.; Johannsmann, D. Correlation between Particle Deformation Kinetics and Polymer Interdiffusion Kinetics in Drying Latex Films. Langmuir, 2013, 29, 1131711321.

22. Ugur, S. Yargi, O.; Elaissari, A.; Pekcan, O. Oxygen Diffusion into Polymer-Clay Composite Films as a Function of Clay Content and Temperature. Macromol. Symp. 2009, $281,168-173$.

23. Yargi, O.; Ugur, S.; Pekcan, O. Fluorescence Quenching Method for Monitoring Oxygen Diffusion into PS/CNT Composite Films. Prog. Org. Coatings 2013, 76, 1805-1809.

24. Yargi, O.; Ugur, S.; Pekcan, O. Oxygen Diffusion into Multiwalled Carbon Nanotube Doped Polystyrene Latex Films Using Fluorescence Techniques. J. Fluoresc. 2013, 23, 357-366.

25. Ugur, S.; Sunay, M. S. Investigation of Particle Size Effect on Film Formation of Polystyrene Latexes Using Fluorescence Technique. Colloids Surf. Physico. Chem. Eng. Aspects 2016, 510, 283-292.

26. Farhangi, S.; Duhamel, J. Probing Side Chain Dynamics of Branched Macromolecules by Pyrene Excimer Fluorescence. Macromolecules 2016, 49, 353-361.

27. Feng, J.; Winnik, M. A. Effect of Water on Polymer Diffusion in Latex Films. Macromolecules 1997, 30, 4324-4331.

28. Oh, J. K.; Tomba, P.; Ye, X.; Eley, R.; Radekacher, J.; Farwaha, R.; Winnik, M. A. Film Formation and Polymer Diffusion in Poly(vinyl acetate-co-butyl acrylate) Latex Films. Temperature Dependence. Macromolecules 2003, 36, 5804-5814.

29. Crank, J. Infinite and Semi-Infinite Media. The Mathematics of Diffusion, 2nd ed., Oxford University Press: Ely House, London, 1975, Chapter 3, pp 28-32. 
30. Wu, J.; Tomba, J. P.; Winnik, M. A.; Farwaha, R.; Rademacher, J. Effect of Gel Content on Polymer Diffusion in Poly(vinyl acetate-co-dibutyl maleate) Latex Films. Macromolecules 2004, 37, 4247-4253.

31. Liu, Y.; Schroeder, W.; Soleimani, M.; Lau, W.; Winnik, M. A. Effect of Hyperbranched Poly(butyl methacrylate) on Polymer Diffusion in Poly(butyl acrylate-co-methyl methacrylate) Latex Films. Macromolecules 2010, 43, 6438-6449.

32. Williams, M. L.; Landel, R. F.; Ferry, J. D. The Temperature Dependence of Relaxation Mechanism in Amorphous Polymers and Other Glass-Forming Liquids. J. Am. Chem. Soc. 1955, 77, 3701-3707.

33. Child, W.; Ferry, J. D. Dynamic Mechanical Properties of Poly- $n$-Butyl Methacrylate. Colloid Sci. 1957, 12, 327-341.

34. Ferry, J. D.; Strella, S.Dielectric Dispersion in Methacrylate Polymers and Its Correlation with Mechanical Properties. Colloid Sci. 1958, 13, 459-471.

35. Ferry, J. D.; Fitzgerald, E. R.; Johnson, M. F.; Grandine, L. D. Mechanical Properties of Substances of High Molecular Weight. X. The Relaxation Distribution Function in Polyisobutylene and its Solutions. J. Appl. Phys. 1951, 22, 717-722.

\section{Table of Content}

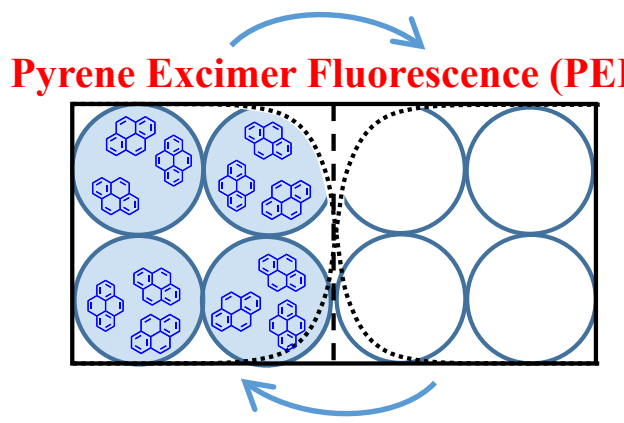

